\title{
"O que veio primeiro: o sujeito do inconsciente ou o sujeito de direitos?": Uma aproximação possível da Psicanálise e das Políticas Públicas ${ }^{165}$
}

\author{
Giovana Telles Jafelice ${ }^{166}$
}

\section{De que adoece o sujeito? Pacto edípico, social e determinantes sociais da saúde}

Já em 1983, Hélio Pellegrino defendia que a ruptura com o pacto social pode implicar o rompimento com o pacto edípico no nível inconsciente, fazendo com que os impulsos deliquenciais pré edípicos, que estavam recalcados, retornem sob a forma de conduta delinquente e antissocial (Pellegrino, 1983). Na idade adulta, um pacto social se soma ao pacto com a Lei da Cultura, estruturado em torno do trabalho, e a isto se acrescenta a sociedade capitalista como fonte de sobre-repressão. À repressão intrínseca ao processo civilizatório se combina a injustiça social: "a má integração da Lei da Cultura, por conflitos familiares não resolvidos, pode gerar conduta anti-social, mas uma patologia social pode também ameaçar - ou mesmo quebrar - o pacto com a Lei do pai” (Pellegrino, 1983).

As ideias de Pellegrino (1983), ainda que de forma experimental, podem ser aproximadas ao trabalho no SUS, que ganha sentido na Reforma Sanitária, a partir dos Determinantes Sociais da Saúde: "os níveis de saúde da população expressam a organização social e econômica do País. (...) Se queremos elevar os níveis de saúde de toda a população, precisamos interferir na estrutura econômica e política do Brasil” (Paim, 2009, p. 12).

\section{O que isto tem a ver com o CAPS?}

Contemporânea à Reforma Sanitária, a Reforma Psiquiátrica foi responsável, a partir do Paradigma da Atenção Psicossocial, por questionar a

\footnotetext{
165 Apresentado em Trabalhos livres no II Simpósio Bienal SBPSP "Fronteiras da Psicanálise: a clínica em movimento" no dia 28 de agosto de 2020.

166 Psicanalista pelo Instituto Sedes Sapientiae e AT. Mestre em Ciências da Saúde e especialista em Saúde Mental pela UNIFESP. Atua em CAPS III e em consultório.
} 
loucura como objeto natural, provocando-nos a pensar em que condições o sujeito fica mais vulnerável ao adoecimento psíquico e quais cuidados podem favorecer a construção de outro lugar social para as pessoas com intenso sofrimento mental. É também neste contexto que se passa a defender o "louco" como "sujeito de direitos".

Trago para reflexão um caso que foi acompanhado no CAPS em que trabalho. D. chegou ao serviço aos 36 anos, após internação em enfermaria de Saúde Mental. Apresentava-se em episódio de mania, com discurso descolado da realidade. Não tinha tido necessidade de cuidados em Saúde Mental anteriormente em sua história. Seu processo de adoecimento se relacionava diretamente ao sofrimento por ter ficado em situação de rua com seus filhos, o que fez com que os dois fossem abrigados.

Após perder a guarda de seu terceiro filho, recém nascido, por seguir em condição de rua (morava em abrigo da Prefeitura) e ter recebido diagnóstico de transtorno afetivo bipolar durante a gestação em outro município, foi definido, de forma vertical pelo Judiciário, que D. fosse atendida em psicoterapia no CAPS. Esta decisão se sustentava no entendimento de alguns profissionais de que, ainda que verbalizasse seu desejo de ser mãe, D. teria "aspectos inconscientes" que indicariam que, na realidade, não desejava ser mãe, uma vez que não cumpria o que os serviços indicavam para retomada da guarda: ir à psicoterapia, ter uma casa e um emprego formal e visitar os filhos no abrigo três vezes por semana no período da tarde.

De forma não surpreendente, D. não aderiu à psicoterapia no CAPS, tendo ido apenas uma vez antes de uma audiência decisiva. Naquela ocasião, não se apresentava em crise, estava trabalhando e tinha expectativa de alugar uma casa para morar com seus filhos. Compreendia, então, que poderia recuperar a guarda das crianças naquela semana. Na audiência, os momentos mais conflituosos se deram em torno do fato de que D. não estava indo à psicoterapia e da disputa entre o Defensor de D. e a Secretaria de Assistência Social, que se negava a conceder benefício eventual à $\mathrm{D}$. e, ao mesmo tempo, questionava a possibilidade de demissão do emprego conseguido por ela. Assim como eu, o Defensor explicava que a "situação social poderia influenciar nas condições psíquicas de D." e que, se havia remissão dos sintomas de mania, apenas o "aspecto social" a impedia naquele momento de retomar a guarda dos filhos, cabendo ao Município 
ser apoio no processo. A (indigesta) impressão que ficava era a de que a cada momento se colocava uma nova exigência (inalcançável) para a reaproximação de D. de suas crianças, pelos estigmas que a envolviam enquanto "mãe portadora de um transtorno mental”. Após esta audiência, D. perdeu o emprego e "enlouqueceu novamente". Ficou em acolhimento integral no CAPS e optou por se mudar para seu município de origem em outro estado.

De forma mais evidente do que em outras situações atendidas no CAPS, a história de cuidados em Saúde Mental de D. mostra-se marcada diretamente pelos “eventos sociais” de sua vida e pela violação de seus direitos. Questionamos, enquanto CAPS, onde estaria o Estado como articulador da possibilidade de retomada da guarda de D. de seus filhos. Na ideia de "proteção”, houve diversas violações de direitos, tanto de D. quanto das crianças, e estas sequer foram observadas enquanto relacionadas diretamente ao adoecimento desta mãe.

\section{Sujeito do inconsciente OU sujeito de direitos? Sujeito do inconsciente $\mathrm{E}$ sujeito de direitos?}

Ao falar do rompimento com o pacto social, estaria Helio Pellegrino se referindo ao sujeito psíquico/sujeito inconsciente ou ao sujeito de direitos? Seriam estes conceitos diferentes?: "sujeito de direitos e sujeito do inconsciente: termos que se opõem, se sobrepõem ou se complementam? Podem coexisitir em um mesmo equipamento de Atenção Psicossocial práticas orientadas por estes conceitos?” (Bueno, 2016, p. 217).

Segundo Bueno (2016), não há vantagem teórico-operacional para a Atenção Psicossocial em trabalhar com a equivalência destas noções:

A escuta das reivindicações deve estar para além do discurso dos direitos. (...) Responder ao enunciado da reinvindicação por direitos sem aproximar-se da questão concernente ao desejo é arriscar-se a (...) perder a posição transferencial (...). A separação entre reivindicação e demanda deve ser uma tática norteadora para a Atenção Psicossocial (...). (Bueno, 2016, p. 222)

Mesmo que concorde em parte com a posição de Bueno (2016), considerando também a multiplicidade envolvida na compreensão do que é o sujeito de direitos, questiono como pode se dar a emergência e sustentação do 
sujeito do inconsciente sem que os direitos básicos estejam garantidos na sociedade em que ele entrará/ viverá:

O pobre absoluto não tem porque manter o pacto social com uma sociedade que o reduz a uma condição de detrito (...) Ele tem toda razão de odiar - e repelir - esta sociedade. Ao romper com o pacto social (...) rompe (...) com a Lei da Cultura. (...) É preciso mudar o modelo econômico social brasileiro (...)" (Pellegrino, 1983)

Onocko-Campos (2014) observa o "grau de miserabilidade" das populações atendidas no SUS e o "grau de esgarçamento simbólico" percebido em comunidades que privilegiam o matar ao conversar. Destaca a necessidade dos próprios usuários fornecerem as "pistas de potencialidades escondidas" nos territórios, bem como que a pobreza não deve fazer supor a total ausência de recursos. Sem esta aproximação acaba-se por produzir apenas controle social (Onocko-campos, 2014). Defende que o trabalho em saúde deve buscar mudar o mundo não pelos usuários, mas com eles, na construção de protagonismo da própria vida (Onocko-campos, 2014).

Neste sentido, destaco a inversão que acontece quando as pessoas que atendemos enquanto Estado deixam de ser sujeitos das Políticas Públicas para serem delas objeto (Onocko-campos, 2014). Sob a égide da proteção (de quem?), acabamos por usar as Políticas Públicas de modo a produzir ainda mais sofrimento, sem escutar o sujeito e respeitar suas possibilidades e desejos. De modo simplificado, compreendo que este processo se dá quando separamos os sujeitos de direitos dos sujeitos do inconsciente, fazendo com que estes sejam operadores não diferentes, mas desarticulados.

Retomando a provocação do título deste trabalho, não falo de "um primeiro" entre sujeito do inconsciente e sujeito de direitos. Quando deixam de ser entendidos em sua forma abstrata enquanto operadores conceituais, as duas ideias se encarnam, efetivamente, no mesmo sujeito, o "sujeito do sofrimento", que chega ao CAPS e terá que se haver com seus direitos e com seu inconsciente, tentando, ao mesmo tempo, sobreviver. Violada em seus direitos, D. foi também questionada em seu "inconsciente": acusada de não poder retomar a guarda dos filhos por não "querer de verdade" o que enunciava. Estaria, aqui, o próprio Estado colocando "em primeiro" o sujeito do inconsciente para justificar sua não garantia do sujeito de direitos? Como poderá D. ser/ desejar ser mãe sem alguns direitos garantidos? 
A partir disto, não posso deixar de defender a necessidade de Políticas Públicas que garantam condições (mínimas?) para que o sujeito do inconsciente possa existir e conviver. Garantir condições não significa, por si só, o estabelecimento do "sujeito da saúde", mas parece ser fundamental para que a narrativa do sujeito inconsciente/ do desejo possa se sustentar e, nos casos de maior vulnerabilidade, até mesmo ser criada.

Finalizo, mais uma vez com Bueno (2016), que nos remete à Reforma Psiquiátrica:

\begin{abstract}
Não devemos substituir o discurso médico pelo discurso dos direitos, mas sim pela multiplicidade discursiva. (...) Uma porta de entrada para o psicanalista que tem como princípio ético fundamental guardar o lugar de emergência da singularidade, do sujeito do inconsciente e da verdade do desejo. (...) A contribuição do psicanalista é abrir espaço dentre tantos discursos para a narrativa do próprio sujeito, contada em primeira pessoa, e que essa narrativa contada seja levada em conta nas decisões multiprofissionais (Bueno, 2016, p. 223).
\end{abstract}

\title{
Referências
}

Bueno, P. A. T. (2016). Sujeito do inconsciente e sujeito de direito: ponto de conjunção ou de disjunção na interlocução da psicanálise com a saúde mental? Stylus Revista de Psicanálise do Rio de Janeiro, 33, 217-55.

Onocko-campos, R. (2014). Psicanálise e saúde coletiva: Interfaces. São Paulo: Hucitec. $2^{\mathrm{a}}$ ed. Coleção Saúde em Debate.

Paim, J. (2009). O que é o SUS. Rio de Janeiro: Fiocruz. Coleção Temas em Saúde.

Pellegrino, H. (1983). Pacto edípico e pacto social (da gramática do desejo à semvergonhice brasílica). Folha de São Paulo: 11 de setembro de 1983. Disponível em:https://pt.scribd.com/document/130397623/PELLEGRINO-Pacto-Edipicoe-Pacto-Social-Da-Gramatica-Do-Desejo-A-Sem-Vergonhice-Brasilica 